\title{
Equilibria under Liability Rules: How the standard claims fall apart
}

\author{
Allan M Feldman \\ Email: allan_feldman@brown.edu \\ Department of Economics, \\ Brown University \\ Ram Singh \\ E-mail: ramsingh@econdse.org \\ Department of Economics, \\ Delhi School of Economics
}

\section{Working Paper No. 315}

http://www.cdedse.org/pdf/work315.pdf

\author{
Centre for Development Economics \\ Delhi School of Economic \\ Delhi-110007
}




\title{
EQUILIBRIA UNDER LIABILITY RULES: HOW THE STANDARD CLAIMS FALL APART
}

\author{
ALLAN FELDMAN $^{\dagger}$ AND RAM SINGH $^{\ddagger}$
}

\begin{abstract}
In many accident contexts, the accident harm depends on observable as well as unobservable dimensions of the precaution exercised by the parties involved. The observable dimensions are commonly referred to as the 'care' levels and the unobservable aspects as the 'activity' levels. In a seminal contribution, Shavell (1980) extended the scope of economic analysis of liability rules by providing a model that allows for the care as well as activity level choices. Subsequent works have used and extended Shavell's model to predict outcomes under various liability rules and also to compare their efficiency properties. These works make several claims about the existence and efficiency of equilibria under different liability rules, without providing any formal proof. In this paper, we reexamine the prevalent claims in the literature using the standard model itself. Contrary to prevalent claims, we show that the standard negligence liability rules do not induce equilibrium for all the accident contexts admissible under the model. Under the standard model, even the 'no-fault' rules can fail to induce a Nash equilibrium. In the absence of an equilibrium, it is not plausible to make a claim about efficiency of a rule per-se or vis-a-vis other rules.

We show that even with commonly used utility functions that meet all the requirements of the standard model, the social welfare function may not have a maximum. In many other situations fully compatible with the standard models, a maximum of the social welfare function is not discoverable by the first order conditions. Under the standard models, even individually optimum choices might not exist. We analyze the underlying problems with the standard models and offer some insights for future research on this subject.
\end{abstract}

Keywords. Observable and Non-observable Care, Activity Levels, Negligence Liability, No-fault Liability, Second Best, Nash equilibrium, Accident Loss, First Best

Acknowledgment. This work has benefited from our interactions with Satish Jain and Hans-Bernd Schaefer. Drupad Nair provided an excellent research support. Institutional support by the Centre for Development Economics, Delhi School of Economics and the University of Delhi are gratefully acknowledged. We are responsible for errors, in any.

$\dagger$ Department of Economics, Brown University. Email: allan_feldman@brown.edu.

$\ddagger$ Department of Economics, Delhi School of Economics, University of Delhi. Email: ramsingh@econdse.org. 


\section{INTRODUCTION}

In many accident contexts, the accident loss and the probability of an accident depend on observable as well as unobservable dimensions of the care exercised by the parties involved. In the literature on liability rules, the observable dimensions are commonly called the 'care' levels and the unobservable aspects of care are referred to as the 'activity' levels. In a pioneering contribution, Shavell (1980) extended the scope of economic analysis of liability rules by providing a model that allows choices of care and activity levels by the parties involved. Shavell's framework provides conditions relevant for the individual utility/ benefit functions and the accident loss function. It has served as a standard model for much of the subsequent works, including Shavell (1987), Endres (1989), Miceli (1997 p. 29), Cooter and Ulen (2004, pp. 332-33), Dari-Mattiacci (2002), Delhaye (2002), Goerke (2002), Parisi and Fon (2004), Singh (2006), Singh (2009), Parisi and Singh (2010), Dari-Mattiacci, Lovat and Parisi (2014), Guerra (2015), Carbonara, Guerra and Parisi (2016), Miceli (2017, Ch 2) among others. ${ }^{1}$

For the most part, existing literature on the subject has focused on examining properties of equilibrium outcomes under the standard rules - the rules of strict liability, no-liability, and the negligence liability based rules; namely, the rule of simple negligence, the rule of negligence with a defense of contributory negligence, the rule of negligence with a defense of comparative negligence, and the rule of strict liability with a defense of contributory negligence. In important contributions, Dari-Mattiacci, Lovat and Parisi (2014) and Carbonara, Guerra and Parisi (2016) have extended the analysis beyond the standard rules to examine the efficiency of rules that permit sharing of liability between non-negligent parties.

Literature Re-examined. In this paper, we re-examine some of the existing claims about the equilibrium outcomes under liability rules and their efficiency properties. As to the existence of equilibria, the standard literature based on the standard model and its generalizations has made the following claims. ${ }^{2}$

First, under the rule of negligence (with or without defense of contributory negligence), the injurer's activity level will be excessive, i.e., greater than the socially optimum level of his activity. However, the victim will make efficient choices, given the inefficient activity choice by the injurer. Analogously, under the rule of strict liability with defense of contributory negligence, the victim's activity level will be inefficiently high, but the injurer's choices will be efficient.

Second, equilibria exist under the negligence liability rules. This claim also follows from the first claim - otherwise, it will be pointless to talk about the outcome under liability rules. Some works have argued that the negligence criterion based liability rules induce

\footnotetext{
${ }^{1}$ For works dealing with the doctrinal foundations of liability and models with constant activity levels, see Polinsky (1980), Landes and Posner (1987), Miceli (1997), Hylton (2001), Jain and Singh (2002), Schfer and Frank (2009), Feldman and Singh (2009), Cooter and Ulen (2004), BarGil and Ben Shahar (2003), Singh (2003, 2007). Also see, e.g., Emons (1990). For applications of the model in other contexts, see Singh (2004 and 2009).

${ }^{2}$ See Shavell (1980), Shavell (1987), Endres (1989), Miceli (1997 p. 29), Cooter and Ulen (2004, pp. 33233), Dari-Mattiacci (2002), Delhaye (2002), Goerke (2002), Parisi and Fon (2004), Singh (2006), Parisi and Singh (2010). For a discussion, see Dari-Mattiacci, Lovat and Parisi (2014, page 572), Carbonara, Guerra and Parisi (2016), and Miceli (2017, Ch 2).
} 
equilibria in which the injurer and the victim opt for care levels that are appropriate from the view point of first-best efficiency. ${ }^{3}$

We re-examine these claims by using commonly used utility and accident loss functions that satisfy all the conditions in the standard model. We strictly follow all the procedures prescribed in the standard model, including the procedure for setting of due care standards for both parties, etc. Yet, contrary to the common belief, we show that depending on the accident context and the liability rule used, a Nash equilibrium may or may not exist. In other words, the existence of a Nash equilibrium under negligence based liability rules cannot be taken for granted. We show that even the rule of strict liability and the rule of no-liability for the injurer fail to induce equilibrium under the standard models.

As far as the efficiency analysis is concerned, liability rules can be compared with one another by comparing the Nash equilibria induced by the rules under consideration. ${ }^{4}$ The above cited literature has focused on efficiency properties of the negligence based liability rules, implicitly assuming that these rules are more efficient than the rules of strict liability and the rule of no-liability. In contrast, we will show that for standard negligence based rules it is not plausible to make a general claim about their efficiency properties, since under these rules existence an equilibrium itself cannot be taken for granted. For the same reason any claim about the relative efficiency of a negligence based liability rules vis-a-vis any other rule including the rule of strict liability can be shaky. Moreover, we show that even in the context were a negligence based rule induces a Nash equilibrium, it may be dominated by the rule of strict liability or the rule of no-liability.

To investigate the above issues further, we examine the nature of the individual payoff functions and the social welfare function under the standard models. We show that the standard models have inherent problems. For several commonly used specifications of these models, even for individuals the optimum choices may not exit.

What is even more serious, the social welfare function in the standard model does not possess properties assumed in the literature. For many accident contexts and commonly used utility functions that meet all the standard conditions, the social welfare function does not have a maximum, in which case the negligence standards would not be defined, let alone a Nash equilibrium of the games induced by the negligence based rules. In many other cases fully compatible with the standard models, the first best (the maximum of social welfare function) may exist but may not be interior. A corner maximum is not a problem per-se. What is problematic is the analytical framework induced by the standard model is inherently prone to generating corner maxima. Simply put, the standard models are not appropriate for risky situation that require significant and comparable activity levels from both parties; such as, motor vehicle accidents.

The Related Literature. Two of the relatively recent works are especially relevant for our study. These are the significant contribution by Dari-Mattiacci, Lovat, and Parisi (2014) and a follow up study by Carbonara, Guerra and Parisi (2016). These works have shown that in some accident settings, the sharing of liability between non-negligent parties

\footnotetext{
${ }^{3}$ See Miceli (1997 p. 29), Cooter and Ulen (2004, pp. 332-33), and research papers Dari Mattiacci (2002), Parisi and Fon (2004), also see Delhaye (2002) and Miceli (2017, Ch 2). For an exhaustive review of the literature on this and related issues, see Guerra (2015).

${ }^{4}$ In particular, rule $\mathrm{A}$ is more efficient to rule B if the Nash equilibrium under rule A implies higher social welfare level than the Nash equilibrium under rule B.
} 
does not dilute incentives for parties to take due care. Moreover, splitting of the accident loss between non-negligent parties enhances the efficiency of negligence liability rules under certain conditions. These results have been derived for particular accident contexts where the activity choice of one party does not depend on care choice by the other party.

We show that in several accident settings under the standard model, the rule of strict liability and/ or the rule of no-liability can be more efficient than a liability sharing rule. However, our findings do not contradict the ones in Dari-Mattiacci et al. (2014), as the accident contexts studied are different.

Some other works have suggested that the efficiency of the rules of negligence can be improved by raising the due care standard for injurers. See Goerke (2002) and Shavell (2007). ${ }^{5}$ These works also implicitly assume that the negligence based rules induce and continue to induce a Nash equilibrium, even when the due care standard are changed. Our analysis shows that for a negligence based rule existence of an equilibrium can also depend on the due care levels.

Section 2 summarizes the standard models used in existing literature including the standard approach towards the social welfare maximizing care and activity levels for the parties. Section 3 shows how the claims in literature about existence of equilibrium under negligence liability rules do not hold. In Section 4, we explain the nature of underlying problems with the standard models. In Section 5, we discuss the problems with the efficiency analysis of liability rules. In Section 6, we discusses conclusions and shortcomings of our analysis.

\section{The Standard Model and its extensions}

\subsection{Basics}

Following the notations in Dari-Mattiacci, Lovat and Parisi (2014), there are two people, $U$ and $V$. They engage in activities that create a risk of an accident. Both parties are private benefit maximizing and risk-neutral individuals. While $U$ is the potential injurer, $V$ is the potential victim. That is, if an accident takes place, person $U$ will be the injurer and person $V$ will be the victim. We will use terms 'the injurer' and 'party $U$ ' interchangeably. Similarly, for 'the victim' and 'party $V$ '. Entire accident costs fall initially on the victim, $V$. A court adjudicates any dispute between $U$ and $V$ over the accident loss.

For example, $U$ may be the driver of a large old truck in rough condition, and $V$ may be the driver of an expensive new BMW. They share the same roads. If they collide, all damages will fall on $V$. Alternatively, $U$ may be a soldier practicing shooting in a forest area, and $V$ may be a nearby stroller. If a bullet misses its target, all damages may fall on $V$.

Each person makes two choices: a level of 'care' and an 'activity' level. For instance, in the old-truck new BMW example, each driver can vary his level of care (controlling their speed, obeying traffic signals, remaining sober, etc, all of which are translated into a 'care' level, measured in dollars). Parties can also vary their activity level. The activity level might be miles driven, for instance.

Formally, care levels for $U$ and $V$ are $x$ and $y$, respectively. These variables are observable by $U$ and $V$, and by the court. The activity levels for $U$ and $V$ are denoted by $s$ and $t$,

\footnotetext{
${ }^{5}$ For a discussion, see Singh (2006) and Dari-Mattiacci, Lovat, and Parisi (2014).
} 
respectively. These are not observable by the court. All 4 variables, $s, x, t$ and $y$, are non-negative. The care levels $x$ and $y$ are measured in dollars. Depending on the nature of the activity, activity levels may be measured in some other unit, for instance number of miles driven.

Let $U(s, x)$ be the benefit (utility) function for the injurer. It depends on his activity level $s$ and his care level $x$. Benefit is measured in dollars. Similarly, the victim $V$ has a utility/ benefit function $V(t, y)$ that depends on his activity level $t$ and his care level $y$. This is also measured in dollars. Both benefit functions have the usual smoothness properties and are public knowledge. Additional properties of these utility functions are discussed in the next section.

The severity of an accident might depend on $x$ and $y$, but the probability of an accident might depend on $s$ and $t$, as well as on $x$ and $y$. Formally, the accident (prevention) technology is captured by the function $L(s, x, t, y)$. It denotes the expected value of the accident loss. $L(s, x, t, y)$ is decreasing and convex in $x$ and $y$ but increasing and weakly convex in $s$ and $t$. In general, $L(s, x, t, y)$ will vary across accident contexts. For instance, in the event of an accident, if the loss suffered by the victim is a constant, $D$, and the probability of accident is given by function $p(s, x, t, y)=\frac{s t}{1+x+y}$, then $L(s, x, t, y)=p() D=$. $\frac{s t D}{1+x+y}$.

\subsection{The Standard model and its Extensions}

In general, different accidents involve different combinations of injurers and victims. One accident may involve an old truck and a new BMW, the another may involve a car hitting a pedestrian, or a practicing shooter injuring, by mistake, a nearby stroller, etc. A particular accident context can be characterized by specifying the identities of potential injurer and victim involved along with the properties of the accident loss reduction technology. Formally, a particular accident context can be characterized by the choice of specific payoff functions $U($.$) and V($.$) for the injurer and the victim, along with the expected loss func-$ tion $L($.$) . The individual preferences (utility/ payoff functions) can vary across injurers and$ victims. Therefore, the exact specification of payoff functions $U($.$) and V($.$) will vary across$ accident contexts.

Moreover, the magnitude of loss in the event of an accident generally depends on the contexts, e.g., the type of vehicles involved in the accident. It is also plausible that the effectiveness of care may vary across injurers and victims - some people may be better at exercising care than the others. So, exact properties of $L($.$) can vary across accident$ contexts.

In any given accident situation, i.e., for any given combination of $U(),. V($.$) and L($.$) ,$ there is a Net Social Benefit or NSB. This is given by:

$$
N S B(s, x, t, y)=U(s, x)+V(t, y)-L(s, x, t, y)
$$

Since different accident contexts correspond to different choices (functional forms) of the functions $U(),. V($.$) and L($.$) , and vice-versa. Therefore, the N S B($.$) function also varies$ across accident contexts.

The accident models in Dari-Mattiacci, Lovat and Parisi (2014) and Carbonara, Guerra and Parisi (2016) are among the most general accident models used in the literature. These 
models admit any accident context from the following class of functions: ${ }^{6}$

$$
\mathbf{G}= \begin{cases}U(s, x): & U_{x}<0, U_{x x} \leq 0, U_{s}>0, \text { and } U_{s s}<0 \\ V(t, y): & V_{y}<0, V_{y y} \leq 0, V_{t}>0, \text { and } V_{t t}<0 \\ L(s, x, t, y): & L_{x}(.)<0, L_{y}(.)<0, L_{s}(.)>0, L_{s s}(.) \geq 0 \\ & L_{t}(.)>0, L_{t t}(.) \geq 0, \text { and } L_{s t}(.) \geq 0\end{cases}
$$

It is easy to produce many different functional forms for $U(),. V($.$) and L($.$) satisfying$ properties in (2.1). Indeed, the general class $\mathbf{G}$ admits infinitely many accident contexts, represented by different combinations of functional forms for $U(),. V($.$) and L($.$) .$

As to the standard model used in Shavell (1980 and 1987) and subsequent literature, the expected loss is defined as $L=\operatorname{st} l(x, y)$ and the parties' utility functions are specified as $U=u(s)-x s$ and $V=v(t)-y t$ with the interpretation that functions $u(s)$ and $v(t)$ denote the gross benefits to $\mathrm{U}$ and $\mathrm{V}$, from their respective activities. The terms $s x$ and $t y$ are interpreted as the cost of care for the injurer and the victim, respectively. ${ }^{7}$ In other words, the standard model puts some structure on the forms of functions $U(),. V($.$) and$ $L($.) considered.

In fact, there are two versions of the standard model. The first version admits the following class of functions: ${ }^{8}$

$$
\mathbf{S} 1= \begin{cases}U(s, x)=u(s)-x s: & u_{s}>0, \text { and } u_{s s}<0 \\ V(t, y)=v(t)-y t: & v_{t}>0, \text { and } v_{t t}<0 \\ L(s, x, t, y)=\operatorname{stl}(x, y): & l_{x}(.)<0, l_{y}(.)<0\end{cases}
$$

This version of the standard model, takes the benefit function for the injurer, $U$, to be a decreasing function of care level $x$. The gross benefit function for the injurer, $u($.$) , is$ assumed to be an increasing and strictly concave function of the activity level, $s$. Similarly, $V$ assumed to be a decreasing function of care level $y$, but $v($.$) is taken as an increasing and$ strictly concave function of $t$.

One can produce many different functional forms for $u(),. v($.$) and l($.$) , all consistent$ with the properties of $\mathbf{S} 1 .^{9}$

Under the second version of the standard model, gross marginal benefit to a party from its activity are assumed to become negative beyond some threshold. Formally, $u($.$) starts$ as an increasing function of $s$ but eventually becomes a declining function beyond some activity level. Likewise for $v($.$) and t$. The second version admits the following class of functions: ${ }^{10}$

$$
\mathbf{S} 2= \begin{cases}U(s, x)=u(s)-x s: & u_{s s}<0, u_{s}>0 \text { for } s<\hat{s} \text { and } u_{s}<0 \text { for } s>\hat{s} \\ V(t, y)=v(t)-y t: & v_{t t}<0, v_{t}>0 \text { for } t<\hat{t} \text { and } v_{t}<0 \text { for } t>\hat{t} \\ L(s, x, t, y)=\operatorname{stl}(x, y): & l_{x}(.)<0, l_{y}(.)<0\end{cases}
$$

\footnotetext{
${ }^{6}$ Carbonara et al. (2016) have considered relaxing the concavity assumption as well.

${ }^{7}$ For more on these specifications, see Dari-Mattiacci et al. (2014, page 575).

${ }^{8}$ See Parisi and Fon (2004), Shavell (2007 a and b), Parisi and Singh (2009), Dari-Mattiacci, Lovat, and Parisi (2014), and Miceli (2017).

${ }^{9}$ Some of the commonly used utility functions belong to this class, e.g., $u(s)=\alpha \sqrt{s}, u(s)=\alpha s^{k}, u(s)=$ $\log (m+s)$, and $u(s)=\alpha \frac{\sqrt{s}}{\sqrt{1+s}}$, where $\alpha>0, k<1$ and $m \geq 1 ; v(t)=\gamma \sqrt{t}, v(t)=\gamma t^{k}, v(t)=\log (m+t)$, and $v(t)=\alpha \frac{\sqrt{t}}{\sqrt{1+t}}$, where $\alpha>0, k<1$ and $m \geq 1$.

${ }^{10}$ E.g., see Miceli (1997), Shavell (1980) and (1987) and Singh (2006).
} 
where $\hat{s}>0, \hat{t}>0$.

Several leading utility functions fall in the class $\mathbf{S} 2 .{ }^{11}$ In fact, $\mathbf{S} 1$ as well as $\mathbf{S} 2$ admit infinitely many accident contexts - due to various possible forms of $U($.$) or V($.$) or L($.$) all$ of which can be shown to satisfy all properties required by these classes.

Moreover, key properties of both versions of the standard model are: ${ }^{12}$

$$
\begin{aligned}
& s=0 \Rightarrow L(s, x, t, y)=0 \\
& t=0 \Rightarrow L(s, x, t, y)=0 \\
& L_{s t}(.)>0 .
\end{aligned}
$$

Informally put, the types of accidents covered by the standard model are the ones that can happen only when activity levels are positive for both the parties. In addition, the marginal effect of the activity of a party on the accident loss is strictly increasing in the activity of the other party. In the context of bilateral-care and bilateral-activity accidents, these are highly intuitive and plausible assumptions. It is common to assume that for the classes $\mathbf{S} 1$, $\mathbf{S} 2$ and $\mathbf{G}, U(0, x)=0=V(0, y)$.

The standard model and all its extensions define the social welfare maximization problem as follows:

$$
\max _{s, x, t, y}\{N S B(s, x, t, y)=U(s, x)+V(t, y)-L(s, x, t, y)\}
$$

It is standard to assume that for the functions $U(),. V($.$) and L($.$) admissible under \mathbf{G}, \mathbf{S} 1$ and $\mathbf{S} 2$, are such that the social welfare maximization problem (2.5) has a unique solution (see Shavell (1980, 1987), Dari-Mattiacci et al. (2014, p 576) among others). The solution, denoted $\left(s^{*}, x^{*}, t^{*}, y^{*}\right)$, is assumed to be fully identifiable by solving the first-order conditions (FOCs):

$$
\begin{array}{r}
U_{s}(s, x)-L_{s}(s, x, t, y)=0 \\
U_{x}(s, x)-L_{x}(s, x, t, y)=0 \\
V_{t}(t, y)-L_{t}(s, x, t, y)=0 \\
V_{y}(t, y)-L_{y}(s, x, t, y)=0
\end{array}
$$

\subsection{Liability: Negligence and No-fault}

When an accident occurs, the victim $V$ initially incurs the entire loss. Afterwards, a court adjudicates the dispute between $U$ and $V$. That is, the court determines what part of the loss will fall on each of the two parties. Under the standard model, a court determines the share of damages to fall on each of the two parties, contingent only on the chosen care levels - since activity levels cannot be observed by courts or since legal restrictions prohibit taking activity levels into account. Specifically, the literature based on the standard model assumes that the court cannot observe $s$ and $t$, but it can observe $x$ and $y$. Accordingly, the court determines the share of the injurer, $\lambda$, in the accident loss as function of $x$ and $y$. The share of loss remaining with the victim is $1-\lambda(x, y)$.

\footnotetext{
${ }^{11}$ E.g., $u(s)=s(\delta-s), u(s)=\alpha \frac{\sqrt{s}}{\sqrt{1+s}}-\delta s, u(s)=\alpha \sqrt{s}-\delta s, u(s)=\alpha s^{k}-\delta s$, and $u(s)=\log (m+s)-\delta s$, where $\alpha, \delta>0, k<1, m \geq 1 ; v(t)=t(\delta-t), v(t)=\alpha \frac{\sqrt{t}}{\sqrt{1+t}}-\delta t, v(t)=\gamma \sqrt{t}-\delta t, v(t)=\gamma t^{k}-\delta t$, and $v(t)=\log (m+t)-\delta t$, where $\alpha, \delta>0, k<1, m \geq 1$.

${ }^{12}$ Note that under $\mathbf{G}$, accident contexts with $L_{s t}()=$.0 are also admissible.
} 
Negligence Liability. Under negligence liability, depending on the rule, the court sets due care standards either for the injurer or for the victim, or for both. Under the standard model, the court uses $x^{*}$ and $y^{*}$ as the due care standards for $U$ and $V$, wherever applicable; where $x^{*}$ and $y^{*}$ come from the profile $\left(s^{*}, x^{*}, t^{*}, y^{*}\right)$, as defined above. Accordingly, a negligence liability based rule determines shares of damages to fall on each of the two parties, contingent on $x, x^{*}$, or on $y$ and $y^{*}$, or contingent on both. The leading negligence-based liability rules can be described as:

1. Simple negligence. This rule says $\lambda=1$ (all the loss is placed on the injurer) if and only if $x<x^{*}$ (the injurer is negligent). Otherwise, $\lambda=0$ (all the loss stays with the victim).

2. Negligence with a defense of contributory negligence. This rule says that $\lambda=1$ if and only if $x<x^{*}$ and $y \geq y^{*}$ (the injurer is negligent and the victim is non-negligent). Otherwise, $\lambda=0$.

3. Strict liability with a defense of contributory negligence. This rule says $\lambda=1$ if and only if $y \geq y^{*}$. Otherwise, $\lambda=0$.

4. Comparative Negligence. This rule says $\lambda=1$ and if and only if $x<x^{*}$ and $y \geq y^{*}$; $\lambda=0$ if and only if $x \geq x^{*}$ (the injurer is non-negligent); and when $x<x^{*}$ and $y<y^{*}$ (both are negligent), the loss is split in proportion to their degrees of negligence.

Besides the above rules, we will consider the following negligence liability based rules.

5. The 50/50 split liability when both are negligent. This rule says that $\lambda=1$ if and only if $x<x^{*}$ and $y \geq y^{*} ; \lambda=0$ if and only if $x \geq x^{*}$; and $\lambda=1 / 2$ and $1-\lambda=1 / 2$ (the loss is split 50/50) when $x<x^{*}$ and $y<y^{*}$ (both are negligent).

6. The 50/50 split liability when both are non-negligent. This rule says $\lambda=1$ and if and only if $x<x^{*} ; \lambda=0$ if and only if $y<y^{*}$ and $x \geq x^{*}$; and $\lambda=1 / 2$ (the loss is split 50/ 50) when $x \geq x^{*}$ and $y \geq y^{*}$ (both are non-negligent).

For the negligence liability based rules, the following axiom holds:

Axiom (A1): Party $U$ is considered negligent if and only if $x<x^{*}$, and similarly, party $V$ is negligent if and only if $y<y^{*}$.

Note that if a party is negligent it does not mean that it will necessarily be liable. For example, under simple negligence rule when $y<y^{*}$ and $x<x^{*}$ hold, only the injurer is liable.

In addition to Axiom (A1), an important property of the above negligence-based liability rules is as follows: When an accident occurs, if a court finds that one of the parties is negligent while the other is not, it places all the damages on the negligent party. We state this property as:

Axiom (A2): $\left[x \geq x^{*} \& y<y^{*} \Rightarrow \lambda=0\right]$ and $\left[x<x^{*} \& y \geq y^{*} \Rightarrow \lambda=1\right]$.

All the liability rules considered in this paper are such that the liability shares of the injurer, $\lambda$, and of the victim, $1-\lambda$, always add up to one. While the liability rules 1-6 
are all negligence-liability based rules, we will refer to rules 1-5 as the standard negligence liability rules given their prevalence in the literature.

No-fault Liability. The next two liability rules are no-fault rules.

7. Strict liability for injurer. This rule says $\lambda=1$ always, i.e., for any $x, x^{*}, y$, or $y^{*}$.

8. No liability for injurer. This rule says $\lambda=0$ always, i.e., for any $x, x^{*}, y$, or $y^{*}$.

These definitions of the strict liability and no liability rules are standard in the literature. The rule of strict liability is a no-fault liability rule since it holds an injurer of accident liable even when the injurer was not at fault (he is not negligent). Similarly, the rule of no liability may hold the victim liable regardless of whether he is at fault or not. These two rules do not satisfy Axiom (A2).

Note that under each of the above liability rules number 1-8, liabilities of the two parties are coupled in that the liability shares $\lambda$ and $1-\lambda$ always add up to one. ${ }^{13}$

\subsection{Individual Choices}

Given that the shares of accident loss are determined by the court in view of the liability rule in force, the injurer and the victim act accordingly. Formally, a liability rule generates a normal form game with $U$ and $V$ as players. Each party wants to choose an activity level and a care level to maximize his benefit function net of the expected damages placed on him by the liability rule. Specifically, given $t$ and $y$ chosen by $V$, the injurer wants to choose $s$ and $x$ to maximize:

$$
U(s, x)-\lambda(x, y) L(s, x, t, y) .
$$

Similarly, given $s$ and $x$ chosen by $U$, the victim wants to choose $t$ and $y$ to maximize:

$$
V(t, y)-(1-\lambda(x, y)) L(s, x, t, y) \text {. }
$$

A Nash equilibrium under a rule serves as a predicted outcome under the rule. Following the mainstream, we consider only pure strategy Nash equilibria while examining equilibrium outcomes under liability rules.

Note that under a liability rule, the sum of the net benefit functions of the injurer and the victim (in the general case) is equal to

$$
U(s, x)+V(t, y)-L(s, x, t, y)=N S B(.) .
$$

\section{Is there An Equilibrium Under Negligence Rules?}

As discussed earlier, the literature claims that standard liability rules induce Nash equilibria. In fact, existence of an equilibrium is taken for granted for standard negligence based rules as as well as for the no-fault liability rules discussed above.

In this section we show that the claims about the existence of equilibria under liability rules do not necessarily hold. We do so by providing several examples of accident contexts that meet all the conditions of standard models, yet none of the standard negligence based

\footnotetext{
${ }^{13}$ In general, a liability mechanism can be called de-coupled if under it, the liability shares do not always add up to one. For a comprehensive analysis of the de-coupled liability when activity levels are constant, see Jain (2004). Also, see Kaur and Kundu (2020).
} 
liability rules induces an equilibrium. We show that even the no-fault rules may fail to induce an equilibrium under the standard model.

3.1. Standard Negligence. To start with, consider the following example corresponding to version 1 of the standard model, i.e., classes $\mathbf{S} 1$.

Example 1: Let $U(s, x)=s^{1 / 2}-x s, V(t, y)=t^{1 / 2}-y t$, accident loss $D=50$ and $L(s, x, t, y)=\frac{50 s t}{1+x+y}$. So,

$$
N S B(.)=s^{1 / 2}-x s+t^{1 / 2}-y t-\frac{50 s t}{1+x+y} .
$$

Consistent with version 2 of the standard model, i.e., class S2, we will work with the following example.

Example 2: Let $U(s, x)=s^{1 / 2}-0.01 s-x s, V(t, y)=t^{1 / 2}-0.01 t-y t$, accident loss $D=50$ and $L(s, x, t, y)=\frac{50 s t}{1+x+y}$. So,

$$
N S B(.)=s^{1 / 2}-0.01 s-x s+t^{1 / 2}-0.01 t-y t-\frac{50 s t}{1+x+y} .
$$

For the accident context in Example 1, the first-order conditions for maximizing the $N S B($.$) ,$ i.e., equations (2.6)-(2.9), lead to the following solution:

$$
\left(s^{*}, x^{*}, t^{*}, y^{*}\right)=(0.0585468,0.355473,0.0585468,0.355473) .
$$

Similarly, for the accident scenario in Example 2, the system of the first-order conditions results in the following solution:

$$
\left(s^{*}, x^{*}, t^{*}, y^{*}\right)=(0.0582945,0.353629,0.0582945,0.353629) .
$$

For the ease of illustration, we have chosen symmetric payoff and loss functions. All numerical computations in this paper are done using Mathematica. Figures are precise up to the sixth decimal point. The Mathematica file with detailed calculations are available on request.

Next, we introduce some terms. Let $s_{d}^{*}$ denote the private benefit maximizing activity level for the injurer when he simply opts for the due care level $x^{*}$, but does not bear any part of the accident costs. Formally, $s_{d}^{*}$ solves

$$
\max _{s}\left\{U\left(s, x^{*}\right)\right\}
$$

Likewise, for the victim, let $t_{d}^{*}$ solve

$$
\max _{t}\left\{V\left(t, y^{*}\right)\right\}
$$

That is, the victim will chose $t_{d}^{*}$ as his activity level if he opts for the due care level $y^{*}$ and gets full compensation for the accident costs. ${ }^{14}$

Now, we turn to the claims in literature about the existence of Nash equilibria under various liability rules. If the claims in the literature are correct, an application of the standard model approach to the above examples should enable us to find an equilibrium under negligence based liability rules, since the chosen examples meet all the conditions of the relevant versions of the standard model.

\footnotetext{
${ }^{14}$ On various interpretations of 'full' compensation, see Singh $(2005,2007)$
} 
In the rest of this section, we investigate existence of a Nash equilibrium. To this end, we will strictly follow the standard procedure towards identification of the first best and setting of due care standards for the parties. Yet, we will show that an equilibrium does not exist under any of the standard negligence based rules; neither does it exist under the rule of strict liability with the defense of contributory negligence. In fact, the rule of strict liability as well as the rule of no-liability for the injurer may also fail to induce an equilibrium. Our first claim is about simple negligence.

Claim 1. Under the rule of simple negligence, a Nash equilibrium is not guaranteed.

Here is why the claim holds. Let's start with Example 1. Consider a choice of care level, say $x$, by party $U$. Recall, for accident context in example $1, x^{*}=0.355473$. The following cases arise.

Case 1: $x>x^{*}$. Obviously, under simple negligence, there cannot be a Nash equilibrium in which party $U$ opts for $x>x^{*}$.

Case 2: $x=x^{*}$. Under the simple negligence rule, by choosing $x^{*} \mathrm{U}$ ensures that all damages fall on $\mathrm{V}$. So he will solve for the payoff maximizing $s$ to go along with $x^{*}$, i.e. he will solve: $\max _{s}\left\{U\left(s, x^{*}\right)=s^{1 / 2}-s x^{*}=s^{1 / 2}-0.355473 s\right\}$; it can easily be checked that his payoff maximizing activity choice is $s_{d}^{*}=1.978455$. That is, in this case the injurer will choose the pair $\left(x^{*}=0.355473, s_{d}^{*}=1.978455\right)$. Given these choices by $U$, party $V$ bears all of the accident loss. So, $V$ will choose $t$ and $y$ that solves

$$
\max _{t, y}\left\{t^{1 / 2}-y t-\frac{50 \times 1.978455 \times t}{1+0.355473+y}\right\} .
$$

Party $V$ 's best response, identified by the FOCs and second order conditions (SOCs), is to choose $t=0.000727586$ and $y=8.59052$. In other words, for the choice of $x^{*}$ by party $U$ to be part of a Nash equilibrium, the following should hold: the choice of $\left(x^{*}=\right.$ $\left.0.355473, s_{d}^{*}=1.978455\right)$ by party $U$ and choice of $(y=8.590, t=0.000727586)$ by party $y$ should be mutually best responses. However, given that $(y=8.590, t=0.000727586)$ is chosen by $V,\left(x^{*}=0.355473, s_{d}^{*}=1.978455\right)$ is not a best response for $U$ because: At $x^{*}$ and $s_{d}^{*}=1.978455$, the payoff for $U$ is 0.70329 ; in contrast, if he opts for $x=0$ with $s=$ 17374.66, his payoff increases to 65.9065. This means that a Nash equilibrium cannot have party $U$ choosing $x^{*}$.

Case 3: $x<x^{*}$. Finally, consider the case, $x<x^{*}$. This would make $U$ negligent under simple negligence liability. So, all damages will fall on $U$, no matter what $V$ does. Therefore $V$ will set his care level $y=0$, and will choose the largest $t$ possible. This means, the victim's problem is to maximize $V(t, 0)=\sqrt{t}$, which has no solution. That is, if $U$ opts for $x<x^{*}$, a best response for the victim does not exist. Therefore, a Nash equilibrium is not possible with the injurer opting for $x<x^{*}$.

Similarly, a Nash equilibrium is not possible under Example 2. Recall, in this case $x^{*}$ $=0.353629$. Repeating the steps in Cases 1 and 2 above, it can easily be seen that there cannot be any Nash equilibrium with $x>x^{*}$ or $x=x^{*}$ opted by $U$. So, consider the case of $x<x^{*}$. Now, $U$ is fully liable. So $V$ will set his care at the minimum level $y=0$, and will choose the activity level $t=2,500$ to maximize his payoff. Given these choices by $V$, there is no best response for $U$ in the region $x<x^{*}$. The choice of $x^{*}=0.353629$ and $s=1.890707$ gives $U$ a payoff of 0.68751 ; any other choice gives him strictly lower payoffs. 
Again, a Nash equilibrium is not possible if the injurer opts for $x<x^{*}$. In other words, a Nash equilibrium cannot exist under the simple rule of negligence.

Next, consider the rule of strict liability with a defense of contributory negligence. This rule is the mirror image of that of simple negligence. Swapping the parties with one another, in view of the symmetry in the functional forms, arguing along the lines in the above claim, it can be seen that the following claim holds:

Claim 2. A Nash equilibrium is not guaranteed under the standard rule of strict liability with a defense of contributory negligence.

Next, we have the following claim.

Claim 3. Under the rule of negligence with a defense of contributory negligence, a Nash equilibrium is not guaranteed.

As under simple negligence, under this rule, party $U$ has no liability as long as $x \geq x^{*}$. Moreover, as long as $x \geq x^{*}$, payoffs and incentive structures are the same for both the parties as under the rule of simple negligence, regardless of the choice of $s$ by $U$ and of $t$ and $y$ by party $V$. So, it is easy to see that there cannot be a Nash equilibrium involving a choice of $x \geq x^{*}$ under the rule of negligence with defense of contributory negligence. Therefore, the only possibility of a Nash equilibrium is when the injurer opts for $x<x^{*}$.

Suppose there is a Nash equilibrium in which party $U$ chooses some $x<x^{*}$. As to the choice of $y$ by party $V$, when $x<x^{*}$, a choice of $y>y^{*}$ is never a best response. So, there are two possibilities for a Nash equilibrium: $y<y^{*}$ or $y=y^{*}$. In the former case, i.e., when $y<y^{*}$, party $V$ is liable under the rule of negligence with defense of contributory negligence, regardless of the choices made by party $U$. Therefore, under an equilibrium in Example 2, $U$ must maximize his gains by choosing care level $x=0$, and $s=2,500$. This is not good for party $V$. Specifically, given $x=0$ and $s=2,500$ opted by $U$ : a choice involving $y<y^{*}$ by party $V$ gives him a payoff less than 0.000354049 ; party $V$ is better off choosing $y^{*}$ and $t=1.890707$ as it gives him a payoff of 0.68751. Therefore, when $x<x^{*}$ and $y<y^{*}$, a Nash equilibrium is not possible.

Finally, consider the case where party $U$ chooses some $x<x^{*}$ but party $V$ opts for $y=y^{*}$. But, this would mean that all damages will fall on $U$, as long as $V$ keeps his $y=y^{*}$. With $y=y^{*}$, the unique best choice for party $V$ is to choose $t_{d}^{*}$, as defined above. In this contexts $t_{d}^{*}=1.890707$. Given these choices by $V$, it can be seen that party $U$ is better off choosing $x^{*}=0.353629$ and $s=1.890707$, thereby getting a payoff of 0.22025 , rather than any other choice involving $x<x^{*}$ that will give $U$ less than 0.0138105. Again, a Nash equilibrium with $x<x^{*}$ is not possible.

Similarly, it can be seen that there is no Nash equilibrium with Example 1 either.

In fact, arguing along the lines of the above claims, we can make the following claim about the rule of 50/50 split liability when both parties are negligent.

Claim 4. A Nash equilibrium is not guaranteed under the rule of 50/50 split liability when both parties are negligent.

This rule differs from the rule of simple negligence and the rule of negligence with a defense of contributory negligence only in the sub-domain of $x<x^{*}$ and $y<y^{*}$. Specifically, in 
the view of the above proofs, it is straightforward to see that under the rule of 50/50 split liability, there cannot be an equilibrium in which $U$ opts for $x \geq x^{*}$; or when $U$ opts for $x<x^{*}$ and $V$ opts for $y \geq y^{*}$. Therefore, we examine the existence of a Nash equilibrium only in the region $x<x^{*}$ and $y<y^{*}$.

In this both parties negligent region, for Example 1, the optimization problem for $U$ becomes: Given $t, y$, solve

$$
\max _{s, x}\left\{s^{1 / 2}-x s-\frac{50 s t}{2(1+x+y)}\right\} \text {. }
$$

The optimization problem for $V$ is: Given $s, x$, solve

$$
\max _{t, y}\left\{t^{1 / 2}-y t-\frac{50 s t}{2(1+x+y)}\right\} \text {. }
$$

These optimization problems give us the following set of first-order conditions:

$$
\begin{aligned}
(1 / 2) s^{-1 / 2}-x-\frac{25 t}{1+x+y} & =0, \\
-s+\frac{25 s t}{(1+x+y)^{2}} & =0
\end{aligned}
$$

and

$$
\begin{aligned}
(1 / 2) t^{-1 / 2}-y-\frac{25 s}{1+x+y} & =0 \\
-t+\frac{25 s t}{(1+x+y)^{2}} & =0 .
\end{aligned}
$$

This system of FOCs has a unique solution: $s=0.086245$ and $x=0.234187, t=0.086245$ and $y=0.234187$. Moreover, in the region $x<x^{*}$ and $y<y^{*}$, the choice of $s=0.086245$ and $x=0.234187$ by party $U$ is a best response to the choice of $t=0.086245$ and $y=0.234187$ by party $V$, and vice-versa. ${ }^{15}$ At these symmetric choices, each party gets a payoff of 0.14948185 . However, if $U$ unilaterally deviates to $x^{*}=0.355473$ and $s_{d}^{*}=1.978455$, it gives him a higher payoff, 0.70329. Hence, in the sub-domain of $x<x^{*}$ and $y<y^{*}$ there cannot exist a Nash equilibrium under this rule.

Similarly, it can be seen that for Example 2 also, there is no Nash equilibrium.

Next, we turn to the rule of comparative negligence. In view of the above arguments, it is obvious that under the comparative negligence rule, there cannot be an equilibrium in which $U$ opts for $x \geq x^{*}$, or when $U$ opts for $x<x^{*}$ but $V$ chooses $y \geq y^{*}$. So, the only possible Nash equilibrium choices are $x<x^{*}$ by $U$ and $y<y^{*}$ by $V$. Under both parties negligent region, there cannot exist a symmetric Nash equilibrium under the rule of comparative negligence. To see, consider Example 2. In view of the arguments presented for Claim 4, it is easy to see that the only candidate for a symmetric Nash equilibrium is: $s=0.086245$ and $x=0.234187$ opted by party $U$, and $t=0.086245$ and $y=0.234187$ chosen by party $V$. However, if $U$ unilaterally deviates to $x^{*}=0.353629$ and $s=1.890707$, he gets a higher payoff. Similarly, under Example 2, there cannot exist a symmetric Nash equilibrium under the standard rule of comparative negligence. Due to the complexity of the calculations involved, we have not been able to rule out the possibility of an asymmetric Nash equilibrium with both parties being negligent.

\footnotetext{
${ }^{15}$ That is, the second order conditions hold.
} 
3.2. Beyond Standard Negligence. So far, we have considered the standard negligence based rules that do not allow for sharing of accident loss between non-negligent parties. For the accident contexts in above examples, all of these rules have failed to induce an equilibrium, even though we have strictly followed the standard procedure prescribed for identification of the first best, and for setting the due care standards for the parties.

The problem of non-existence goes beyond the above examples. It can easily be verified that our claims of non-existence also hold for values of $D$ different from $D=50$ in the expected loss function, $L($.$) . Similarly, in Example 2, we have verified the non-existence$ claims by replacing terms $0.01 \mathrm{~s}$ and $0.01 t$ with other similar changes in the benefit functions $U($.$) and V($.$) . Such changes in the expected loss function and/or in the utility functions$ amount to changing the accident contexts. In other words, our claims about non-existence of equilibrium can be shown to hold for many different accident contexts fully compatible with the standard model.

This shows that the prevalent claims about the equilibrium outcomes under standard negligence based liability rules do not hold, in general.

Indeed, the problem of non-existence of equilibrium extends well beyond the above examples and negligence based standard liability rules. Consider the rule of strict liability for injurer. Under this rule $\lambda(x, y)=1$, regardless of the choice of $x$ and $y$ made by the parties. Now take any accident context from class $\mathbf{S} 1$ or class $\mathbf{G}$, discussed above. Under the strict liability rule all damages fall on $U$, no matter what $V$ does. Therefore $V$ will set his care level $y=0$, and will choose the largest $t$ possible. In other words, the victim's problem is to choose $t$ so as to maximize $V(t, 0)$. However, for utilities belonging to classes $\mathbf{S} 1$ or $\mathbf{G}$, marginal benefit from the activity are always positive, i.e., $V_{t}>0$ always; which means the victim would like to increase his activity beyond any limit. That is, a best response for the victim does not exist. Therefore, a Nash equilibrium cannot exist under the rule of strict liability for the injurer. This logic applies to each and every accident contexts in $\mathbf{S} 1$ and $\mathbf{G}$.

Similarly, it can be seen that for classes $\mathbf{S} 1$ and $\mathbf{G}$, a Nash equilibrium cannot exist under the rule of no-liability for the injurer.

To sum up, our results show that the problem of non-existence of equilibrium is a serious concern. Equilibrium cannot be taken for granted. To be clear, our results do not imply that a Nash equilibrium can never exist under a liability rule. Depending on the accident context and the liability rule in force, a Nash equilibrium may or may not exist. To illustrate this, we turn to a rule that splits the accident loss between non-negligent parties, i.e., liability rule number 6 . Interestingly, this rule has a Nash equilibrium!

Claim 5. For accident contexts in Examples 1 and 2, there exists a Nash equilibrium under the rule of 50/50 split liability when both parties are non-negligent.

Specifically, this liability rule works like this: $U$ bears all the loss when he is negligent; that is, when $x<x^{*}$. $V$ bears all the loss when $y<y^{*}$ and $x^{*} \leq x$. When $x^{*} \leq x$ and $y^{*} \leq y$, the loss is split $50 / 50$.

Consider Example 1. From the arguments in Claim 1 above, it can be seen that as under the rule of negligence, under this rule as well, there cannot be a Nash equilibrium involving the choice of $x<x^{*}$ by party $U$, or a choice of $x \geq x^{*}$ by party $U$ and some $y<y^{*}$ by party $V$. Therefore, let us consider the region $x^{*} \leq x$ and $y^{*} \leq y$, with both parties non-negligent. To see that a Nash equilibrium exists, suppose $x^{*}=0.355473$ and $y^{*}=0.355473$ are chosen by $U$ and $V$, respectively. At these care level choices, liability share of each party is $1 / 2$. 
Therefore, the choices of $s$ and $t$ by the parties are characterized by the following FOCs:

$$
\begin{aligned}
& (1 / 2) s^{-1 / 2}-0.355473-\frac{25 t}{1+0.355473+0.355473}=0, \\
& (1 / 2) t^{-1 / 2}-0.355473-\frac{25 s}{1+0.355473+0.355473}=0 .
\end{aligned}
$$

This system has a unique solution with $s=t=0.089838$. Now, it can be seen that given the choice of $(t, y)=(0.089838,0.355473)$ by $V$, the pair $(s, x)=(0.089838,0.355473)$ is a unique best response for $U$ identified by the first and second order conditions, and viceversa. That is, $(0.089838,0.355473,0.089838,0.355473)$ is a Nash equilibrium under the rule of 50/ 50 split liability. Replicating the above steps, it can be seen that for Example 2, $(0.089379,0.353629,0.089379,0.353629)$ is a Nash equilibrium under the rule.

This result also speaks to the issue of loss sharing between non-negligent parties. Claim 5 shows that splitting of accident loss between non-negligent parties, rather than diluting the incentives of the parties to take due care can actually strengthen them. ${ }^{16}$

\section{Problems with the Standard Model}

In this section we turn to some serious issues with the standard model and their implications for the economic analysis of liability rules. We show that for a large set of accident contexts, the social welfare function, $N S B($.$) , either does not have a maximum, or has a$ solution that can not be discovered using the first order conditions. In the next subsection, we will analyze several inherent problems with the standard care-activity models.

\subsection{The Missing Maxima}

In this subsection, we will show that the existence of welfare maximizing care and activity levels cannot be taken for granted in traditional precaution-activity models. Specifically, we will show that for many accident contexts belonging to classes $\mathbf{S} 1, \mathbf{S} 2$ and $\mathbf{G}$, the social welfare function, $N S B($.$) , does not have a maximum at all or does not have an interior$ maximum. Non-technical readers may want to skip the technical details below.

To start with, consider the social benefit function $N S B()=.U()+.V()-.L($.$) generated$ by the benefits and accident loss functions admissible under the first version of the standard model version. E.g., take any $L(.) \in \mathbf{S} 1$ and consider simple forms for $U($.$) and V($.$) , as in$ the following class of functions:

$$
\mathbf{C} 1= \begin{cases}U(s, x)=\alpha s^{k}-s x, & \alpha>0 \text { and } 0<k<1 \\ V(t, y)=\beta t^{j}-t y & \beta>0 \text { and } 0<j<1 \\ L(s, x, t, y) \in \mathbf{S} 1 & .\end{cases}
$$

Clearly $\mathbf{C} 1 \subset \mathbf{S} 1$. For this class, the social welfare as measured by $N S B($.$) becomes:$

$$
N S B(.)=\alpha s^{k}-s x+\beta t^{j}-t y-s t l(x, y) .
$$

Even though the utility functions satisfy the Inada conditions with respect to activity levels, this $\operatorname{NSB}($.$) has no maximum. To see why, fix x=y=t=0$. Now $N S B()=.\alpha s^{k}$. It is

\footnotetext{
${ }^{16}$ Dari-Mattiacci et al. (2014) also show that loss can be shared between non-negligent parties without diluting the care incentives. Their results are derived for accident contexts different from ours.
} 
unbounded in $s$ and approaches $\infty$ as $s \rightarrow \infty$. Alternatively, if we fix $x=y=s=0$ and let $t \rightarrow \infty$, the $\operatorname{NSB}($.$) approaches \infty$. The same logic applies if we replace $u(s)=\alpha s^{k}$ with $u(s)=\log (m+s)$, or replace $v(t)=\beta t^{j}$ with $v(t)=\log (m+t)$ where $m \geq 1$. In fact, this logic applies to any $\operatorname{NSB}($.$) based on the following class \mathbf{C} 2$ :

$$
\mathbf{C} 2=\{U(.), V(.), L(.) \in \mathbf{S} 1 \mid U(.) \text { or } V(.) \text { is unbounded }\}
$$

Even if the Inada conditions are imposed on the utility and expected loss functions the $\mathrm{NSB}($.$) cannot achieve a maximum as long as U($.$) or V($.$) is unbounded from above. To$ see, hold $t=0$. Now, $U($.$) and hence N S B($.$) can be increased beyond limits! In other$ words, the objective of maximizing the $N S B($.$) cannot be achieved.$

Mathematically speaking, the set of functional forms of $U($.$) that are increasing, concave$ and unbounded above in $s$ is infinite. Similarly, infinitely many forms of $V($.$) are increasing,$ concave and unbounded in $t$. On this count itself, the classes $\mathbf{C} 2, \mathbf{S} 1$ and $\mathbf{G}$ each contains infinitely many combinations of $U(),. V($.$) , and L($.$) , for which N S B($.$) cannot be maxi-$ mized. ${ }^{17}$ So, we can conclude that for infinitely many accident contexts, admissible under the standard model and the class $\mathbf{G}$, there exists no maximum.

The problem of non-existence of maxima for the above classes can be attributed to the fact that utilities are unbounded above in $s$ or $t$ but bounded from below. Next, consider the case where utilities are unbounded from below.

First consider $\log$ utilities; $U()=.\log s-s x$ and $V()=.\log t-t y$. For $\log$ utilities, zero activity by either party cannot be the optimum. Using $L(s, x, t, y)=\frac{50 s t}{1+x+y}$, maximization of the $N S B($.$) will solve:$

$$
\max _{s, x, t, y}\left\{\log s-s x+\log t-t y-\frac{50 s t}{1+x+y}\right\} .
$$

The system of FOCs for this problem has a unique solution: $(s, x, t, y)=\left(\frac{2}{9}, \frac{7}{6}, \frac{2}{9}, \frac{7}{6}\right)$. The value of the NSB at this point is -4.26741 . The solution of the FOCs is neither a local maximum nor minimum ${ }^{18}$ However, there are two social welfare maximizing profiles of care and activity levels, i.e., there are two global maxima identified by the Numerical maximization using Mathematica. There are; the point $(s, x, t, y)=\left(1.927 \times 10^{8}, 0,3.698 \times\right.$ $\left.10^{-6}, 104250\right)$ and its mirror image $(s, x, t, y)=\left(3.698 \times 10^{-6}, 104250,1.927 \times 10^{8}, 0\right)$. That is, the social welfare is maximized at a corner point. At each global maximum, the NSB is 5.885 .

In the above and following examples, we deliberately work with symmetric utility and accident loss functions; it is easier to produce corner maximum when the payoff functions are asymmetric.

Next, consider maximization of the following:

$$
\max _{s, x, t, y}\left\{\log s-s x+\log t-t y-\frac{50 s t}{1+\sqrt{x}+\sqrt{y}}\right\} .
$$

This also suffers from similar problems. The system of FOCs has a unique solution: $(s, x, t, y)=(0.211713,0.627753,0.211713,0.627753)$. The value of the NSB at this point is

\footnotetext{
${ }^{17}$ Note $\mathbf{S} 1, \mathbf{S} 2$ are not subset of $\mathbf{G}$.

${ }^{18}$ The FOC solution fails to satisfy the SOCs. The Hessian is neither negative definite nor positive definite. See file 'Log utility combined'.
} 
-4.23795 . The solution fails to satisfy the SOCs. The Numerical maximization using Mathematica gives two global maxima; the point $(s, x, t, y)=\left(7.615 \times 10^{-10}, 4.374 \times 10^{8}, 3.664 \times\right.$ $\left.10^{11}, 0\right)$ and its mirror image $(s, x, t, y)=\left(3.664 \times 10^{11}, 0,7.615 \times 10^{-10}, 4.374 \times 10^{8}\right)$. At each point the NSB is 4.63. Again, the first best solutions (the global maxima) remain corner points. Welfare maximization requires one of the parties to take no care at all and the other to reduce activity level to almost zero.

While attempting to obtain an interior solution, it is difficult to think of functions more suitable than the ones under (4.4). This combination of functions satisfies Inada type conditions, i.e., it guarantees the following for each variable: at the zero level of a variable, the marginal benefit from increasing it is infinite, and marginal gains approach zero as the variable approaches infinity. Still, the first order conditions throw up solution which is neither a maximum nor minimum.

In the above NSB functions, the problem of non-existence of maxima or a corner maximum may be attributable to the fact that utilities considered by us are unbounded. So, let us consider some leading classes of bounded utilities. First, consider:

$$
\mathbf{C} 3= \begin{cases}U(s, x) & =s^{1 / 2}-\delta s-s x \\ V(t, y) & =t^{1 / 2}-\delta t-t y \\ L(s, x, t, y) & =\frac{s t D}{1+x+y}\end{cases}
$$

where $\delta, D>0$. As Table 1 in the Appendix shows, for a large range of parameter $\delta$ and $D$, the global maximum of the NSB function is a corner point, and hence unidentifiable by the first order conditions. Changing the expected loss function also does not seem to help. ${ }^{19}$

A few remarks about the tables in the Appendix are in order. One, each table presents results for different $N S B$ functions derived from the class mentioned at the top of the table. Different $N S B s$ arise corresponding to different combinations of $\delta$ and $D$ in the relevant class mentioned at the top of the table. Two, for each combination of $\delta$ and $D$, i.e., for each $N S B$, we have listed only one of the two corner maxima (the first best solutions). For every maximum listed in the tables, its mirror image is also a maximum. For example, the $1^{\text {st }}$ row of Table $1(\delta=0.1$ and $D=50$ in C3) lists only one social welfare maximizing point $(s, x, t, y)=\left(24.96370,0,5.13773 \times 10^{-5}, 34.32330\right)$, though its mirror image, i.e., $(s, x, t, y)=\left(5.13773 \times 10^{-5}, 34.32330,24.96370,0\right)$ is also a NSB maximizing point. Three, the figures in each cell are precise up to the $5^{\text {th }}$ decimal point.

Next, consider another bounded class.

$$
\mathbf{C} 4= \begin{cases}U(s, x) & =s(\delta-s)-s x \\ V(t, y) & =t(\delta-t)-t y, \\ L(s, x, t, y) & =\frac{s t D}{1+x+y},\end{cases}
$$

where $\delta, D>0$. For a wide range of parametric values belonging to this class, the solution to the NSB maximization problem is not interior. The solution from FOCs is not even a local maximum or a local minimum. See Table 2. Consider yet another class of bounded

\footnotetext{
${ }^{19}$ Even if we change the expected loss function to $\frac{s t D}{1+\sqrt{x}+\sqrt{y}}$ or to $\frac{s t D}{1+s x+s y}$, the NSB(.) continues attain maximum at a corner point.
} 
utilities:

$$
\mathbf{C} 5= \begin{cases}U(s, x) & =\frac{\sqrt{s}}{\sqrt{1+s}}-\delta s-s x, \\ V(t, y) & =\frac{\sqrt{t}}{\sqrt{1+t}}-\delta t-t y \\ L(s, x, t, y) & =\frac{s t D}{1+x+y},\end{cases}
$$

$\delta, D>0$. For every accident context in class $\mathbf{C} 5$, the $N S B$ function is bounded above by 2 . Yet, for many combinations of $\delta$ and $D$, the first best is a corner point, and hence cannot be identified by the FOCs. See Table 3.

In the interest of brevity, tables below present results for a select combination of parameters. However, using the Mathematica code (available on request), it can easily be seen that the results hold for a really large range of parameters. Actually, we have not been able to find functional forms that are compatible with the standard models and deliver an interior maximum.

Summing up, analysis of this sub-section shows that even for leading utility functions used in economics, either a first best solution does not exist or there is no interior first best solution. Specifically, for many accidents in classes $\mathbf{S} 1$ and $\mathbf{G}$, the social welfare function $N S B$ does not have a maximum. Further, we have shown that for many other accidents in C3 - C5 and hence in $\mathbf{S} 2$, a global maximum is corner. It requires very high activity level from one of the parties and essentially zero activity by the other party. The choice of zero activity level by one of the parties has great social benefit of reducing the accident loss to zero. Moreover, it reduces the cost of care for the party to almost zero.

\subsection{The Inherent Problem}

In this subsection, we discuss several 'problems' with the standard model and its generalizations. First of all, under commonly used specification of the standard model the individual optimization problems do not have a solution even under the rule of strict liability and the rule of no-liability. Consider any accident context from class $\mathbf{S} 1$ and/or class G. Suppose the rule in force is of no-liability for the injurer. Under this rule, the injurer is not liable regardless of his choice of care and activity levels. So, he will choose zero care and would want to choose activity level to maximize his private benefit. Formally, his optimization problem for activity is

$$
\max _{s}\{U(s, 0)\}
$$

But, for classes $\mathbf{S} 1$ and $\mathbf{G}, U_{s}>0$ always. This means that there is no utility maximizing choice for the injurer. Similarly, under the rule of strict liability, the victim's maximization problem

$$
\max _{t}\{V(t, 0)\}
$$

has no solution under classes $\mathbf{S} 1$ and $\mathbf{G}$, as $V_{t}>0$ always.

Moreover, $N S B($.$) , i.e., the social welfare function induced by the common specifica-$ tions of the standard model does not possess properties assumed in the literature. Under commonly used specifications of the model, such as classes $\mathbf{C} 1$ and $\mathbf{C} 2$ discussed above, the social welfare function has no maximum value. Notably, these class of accidents meet all the conditions of the model, yet the social welfare function does not have a maximum. As discussed in the last section, this problem arises for infinitely many accident contexts 
from classes $\mathbf{S} 1$ and $\mathbf{G}$. In the absence of a maximum for the social welfare function the negligence standards would not be defined, what to speak of a Nash equilibrium under the negligence rule that might be in place.

These problems arise because of unrealistic properties of classes $\mathbf{S} 1$ and $\mathbf{G}$. Simply put, commonly used specification $\mathbf{S} 1$ and $\mathbf{G}$ imply the following: If a party does not have to take care, its activity is not self-limiting. In other words, if not required to take care, a driver will keep on driving, a pedestrian will keep on walking!

These are implausible and unrealistic assumptions. At a bare minimum the individual payoff functions $U($.$) and V($.$) should be such that the activity levels are self-limiting.$ However it is not enough to have self-limiting benefit functions. As is shown above, even for several commonly used self-limiting utility functions (e.g., as in case of accident classes C3-C5) the first best (which maximizes $N S B$ ) is not an interior point. Consequently, the standard approach of using the first order conditions to identify the first best care levels is misleading in many accident contexts.

The following key feature of the standard models seems to be a source of this problem:

$$
L(.)=0 \text { if } s=0 \text { or } t=0 \text {; see the expression (2.4). }
$$

On the face of it, an intuitive and plausible assumption. However, it makes the model vulnerable to corner global maxima. If one party, say the victim, keeps his activity at zero, it has two direct and significant social benefits. First, the expected accident loss is reduced to zero, even if the injurer opts for very high level of activity and does not exercise care at all. Second, the cost of care for the victim is also reduced to zero, even when he chooses very high care. This second benefit arise from the specification of the cost of care in the standard models - $t y$ for the victim and $s x$ for the injurer. So $t=0$ implies $t y=0$, even if the care level $y$ is very very large.

Our analysis presented above shows that for a large set of accident contexts, these two gains dominate the opportunity cost, i.e, the forgone utility to the victim, which is kept almost at $0 .{ }^{20}$

Therefore, the standard models are vulnerable to corner global maxima. This problem does not go away even with some other specifications of the cost of care, i.e., instead of specifying $s x$ as cost of care for the injurer and $t y$ for the victim, we let these costs be simply $x$ and $y$, respectively. We have also worked with the following costs functions:

$s x+u$ for the injurer and $t y+u$ for the victim. ${ }^{21}$ We have also tried other specifications of the expected loss functions, such as $L()=.\frac{D s t}{(1+x+y+u+v)}$ or $L()=.\frac{D s t}{(1+s x+t y+u+v)}$ but the social welfare functions continue to give corner solutions.

The corner maxima are not a problem per-se. What is problematic is that the analytical framework produced by the standard model is inherently prone to generating too many corner maxima. In other words, the standard models do not provide satisfactory framework for analysis accidents contexts where the socially optimum activity levels are significantly greater than zero for both parties, e.g., road accidents.

${ }^{20}$ This logic applies to positive but arbitrarily small levels of $t$, e.g., in case of log utilities as in (4.3) and (4.4) above.

${ }^{21}$ In this specification, the cost of care has two components. $s x$ can be thought of as injurer's cost of care that increases with activity level, e.g., keeping awake while on wheel. $u$, on the other hand, can be interpreted as the care that does not varies with activity, e.g., the cost of annual regulatory check up of vehicle. 


\section{Problems With the EFficiency analysis}

Focus of the existing literature is on the efficiency properties of the negligence based liability rules. With the exception of Dari-Mattiacci, Lovat, and Parisi (2014), this literature is based on an implicit, at times explicit, assumption that the negligence based rules induce an equilibrium. Moreover, the literature seems to assume that the negligence rules are more efficient than the no-fault rules. However, as we have shown in Section 3.1, one cannot be sure of existence of an equilibrium under any of the standard negligence based rules. In the absence of a Nash equilibrium, it is not plausible to make any claim about efficiency of a rule per-se or vis-a-vis other rules. Specifically, a negligence based liability rule cannot be assumed to be more or less efficient than any other rule including the rule of strict liability without precise specification of the accident context and ensuring existence of equilibria under each of the rules being compared.

This holds true for the no-fault liability rules as well. As is shown in Section 3.2, for a large class of accident contexts in class $\mathbf{S} 1$ and/or class $\mathbf{G}$, a no-fault liability rule may not have a Nash equilibrium. Therefore, it is not plausible to make general claims about efficiency of a liability rule per-se or relative to another rule.

Moreover, by concentrating on presumed inner solutions from first order conditions, the literature has aggravated the problem efficiency analysis. Even when the net social benefit function has a maximum, the individual optimization problems are well defined, and each of the liability rules under consideration induces a Nash equilibrium, a rule of no-fault liability can be more efficient that a liability sharing negligence based rule.

To show this we introduce two terms. Let $s_{0}^{*}$ denote the private benefit maximizing activity level for the injurer when he takes no care at all and yet does not bear any of the accident costs. Formally, $s_{0}^{*}$ solves

$$
\max _{s}\{U(s, 0)\}
$$

Likewise, let $t_{0}^{*}$ denote the benefit maximizing activity level for the victim when he takes no care at all and yet is fully compensated for the accident costs. Mathematically, $t_{0}^{*}$ solves

$$
\max _{t}\{V(t, 0)\} \text {. }
$$

In view of the above, under classes $\mathbf{S} 1$ and/or class $\mathbf{G}$, neither $s_{0}^{*}$ nor $t_{0}^{*}$ exist. However, these are well defined for accidents in $\mathbf{S} 2$. So, we work with an example from this class.

When $s_{0}^{*}$ exists, it is obvious that under the rule of no-liability for the injurer, $U$ will choose zero care along with $s_{0}^{*}$ as the activity. Similarly, when $t_{0}^{*}$ exists, under the rule of strict liability, $V$ will choose zero care along with $t_{0}^{*}$ as the activity.

Now, let us consider the accident context of Example 2. Note that the net social benefit function for this context arises as a special case of functions in C3 if we take $\delta=0.01$ and $D=50$. As can be seen from Row 2 of Table 1, for this $N S B($.$) , there are two corner global$ maxima: $(s, x, t, y)=(2499.96,0,0,352.551)$, and $(s, x, t, y)=(0,352.551,2499.96,0)$. At these points, the $N S B()=$.25.0004 . Note that the first maximum requires very high activity and zero care from the injurer, along with extremely low activity but very high care from the victim, and vice-versa for the second solution.

The first global maximum is achieved as a Nash equilibrium under the rule of no liability for the injurer. Here is why. Since $V$ bears the damages, $U$ sets $x=0$, yet he is not liable for accident loss. So, to maximize his benefit, he chooses $s=s_{0}^{*}$. In this case, $s_{0}^{*}=2,500$. Now, given $x=0$ and $s=2,500$ chosen by $U$, the best response for $V$ is to choose $y=352.5534$ 
and extremely low level of activity at $t=0 .{ }^{22}$ That is, under no liability for the injurer, the Nash equilibrium is: $(s, x, t, y)=(2500,0,0,352.5534)$, resulting in $N S B=25.0004$ which approximates the first of the global maxima.

By symmetry, under the rule of strict liability for the injurer, the equilibrium will be at $(s, x, t, y)=(0,352.5534,2500,0)$; and the value of the $N S B$ at this equilibrium will again be 25.0004. In other words, the equilibrium under the rule of strict liability approximates the second of the global maxima.

Now consider the liability sharing rule 6 , i.e., the rule of 50/50 split liability when both the parties are non-negligent. From Section 3 we know that under this rule the profile

$(0.089379,0.353629,0.089379,0.353629)$ is a Nash equilibrium for the accident context in Example 2. But at this Nash equilibrium point, the value of the $N S B=0.29973$, is much less than 25.0004, the value of NSB at the equilibrium under the rule of no liability as well as the rule of strict liability! Therefore, in some contexts, a no fault liability rule can dominate a liability sharing negligence. Therefore, even in the contexts where equilibria exist, focus on the negligence based rules over the no-fault rules is not justified.

Next consider the claim of increasing the social welfare under a negligence based rule by raising the due care level. This strand of literature also implicitly assumes that the negligence based rules induce and continue to induce a Nash equilibrium, even when the due care standard are changed. ${ }^{23}$ This assumption is also misplaced. Our analysis shows that for a negligence based rule, existence of an equilibrium can also depend on the due care levels. For instance, in the context of Example 2, if the due care level for the injurer is set at zero, then the rule of negligence induces an equilibrium - in that case, the simple negligence rules becomes the rule of no-liability for injurer (a rule that induces an equilibrium, as shown above). However, if the due care level is set at $x^{*}=0.353629$, from Claim 1 above, we know that there cannot exits a Nash equilibrium under the simple negligence rule.

\section{Conclusions and Limitations}

The standard model of accidents introduced in Shavell (1980 and 1987) has been used in much of the subsequent literature on economic analysis of liability rules. This commonly used model specifies conditions on the individual benefit functions and also the accident loss functions. Besides, it prescribes how the due care levels should be chosen under a liability rule. In this paper, we have applied the standard model to several large classes of individual utility functions and loss functions, including the functions commonly used in economics. All functions used by us satisfy all the conditions of the standard model. Moreover, we have followed the approach towards identification of the due care levels and Nash equilibria, exactly as prescribed in the standard model. However, our findings are very different from the claims in the existing literature.

Contrary to the mainstream claims, we have shown that the existence of an equilibrium under a liability rule is not guaranteed; depending on the accident contexts and the rule in force, a Nash equilibrium may or may not exist. This is as much true of negligence based rules as for the no-fault rules, such as, the rule of strict liability and the rule of no liability for the injurer.

\footnotetext{
${ }^{22}$ These $y$ and $t$ are a unique solution to $V$ 's problem: $\max _{t, y}\left\{t^{1 / 2}-0.01 t-y t-\frac{50 \times 2,500 t}{1+y}\right.$. $\}$

${ }^{23}$ See Goerke (2002) and Shavell (2007). For discussion see Singh (2006) and Dari-Mattiacci, Lovat, and Parisi (2014).
} 
This finding has implications for the efficiency analysis of liability rules that has primarily focused on negligence based liability rules. A strand of these works has attempted to examine the effect of changing due care levels on the efficiency of the rule. However, when the existence of a Nash equilibrium itself cannot be taken for granted, it is not plausible to make general claims about efficiency of a rule per-se or vis-a-vis the other liability rules. Specifically, a negligence based liability rule cannot be considered more or less efficient than the rule of strict liability without precise specification of the accident context and ensuring existence of equilibria under each of the rules being compared. Moreover, we have shown that even if a Nash equilibrium exists under a negligence based liability rule, it may be less efficient than a no-fault liability rule. In other words, we have shown that in many accident contexts, the second best rule may be either the rule of strict liability or the rule of no-liability for the injurer.

These implications of the standard models do not gel with the prevalence of negligence liability rules in the real world, suggesting that either the efficiency does not play important role in choice of liability rules or the standard model needs to be revised.

We have shown that the standard model is inherently vulnerable to several problems. For several large classes of functions fully consistent with the standard model, a global maximum does not exist for the net social welfare function; even individual choices not well defined. For many other commonly used specifications of benefit functions, the solution to the social welfare maximization problem is a corner point - it requires very high activity with zero care from one of the parties, along with almost zero activity with very high care from the other party. This is a problem because even with commonly used utility functions, the standard model does not induce accident contexts where social efficiency requires strictly positive care and activity levels from both the parties - for example, road accidents. Our analysis identifies the key features of the standard model that make it vulnerable to corner solutions.

Our results do have several limitations. We do not answer an important question: what properties of utility and accident loss functions can guarantee an interior maximum? Addressing this question is important for the use of the first order conditions as a guide for identifying the first best and also for explaining prevalence of the negligence based rules. However, our analysis offers some insights on these concerns. We hope our findings will be a useful guide for future research on the above issues.

\section{REFERENCES}

Bar-Gill, Oren, and Ben-Shahar, Omri (2003), 'The Uneasy Case for Comparative Negligence', American Law and Economic Review, 5: 433-469.

Carbonara, Emanuela; Guerra, Alice; Parisi, Francesco. (2016) 'Sharing Residual Liability : The Cheapest Cost Avoider Revisited,' The Journal of Legal Studies, Vol. 45, No. 1, 2016, p. 173-201. Cooter, R. D. and Ulen, T. S. (2004), Law and Economics, 4th ed., New York, Addison-Wesley. Cooter, Robert D. and Ulen, Thomas S. (1986), 'An Economic Case for Comparative Negligence', 81 New York University Law Review, 1067-1110.

Delhaye Eef 'Accident Analysis; the role of liability rules'at www.econ.kuleuven.be/ete/downloads/delhaye 2002 liab.pdf as on May 13, 2006

Dari-Mattiacci, Giuseppe and Francesco Parisi (2003), 'The Economics of Tort Law: A Precis ', 170, George Mason Law \& Economics Research Paper No. 03-49. 
Dari-Mattiacci, Giuseppe Bruno Lovat, and Francesco Parisi (2014), 'Loss-Sharing between Nonnegligent Parties', 170, Journal of Institutional and Theoretical Economics, 571-598.

Emons, W. (1990). "Efficient Liability Rules for an Economy with Non-Identical Individuals." Journal of Public Economics, 42, 89104.

Endres, Alfred (1989). 'Liability and Information' Journal of Institutional and Theoretical Economics (JITE), Vol. 145, No. 2, pp. 249-274

Feldman, Allan M. and Frost, John M. (1998), 'A Simple Model of Efficient Tort Liability Rules', 18 International Review of Law and Economics, 201-215.

Feldman, Allan M. and Singh, Ram (2009), 'Comparative Vigilance' American Law and Economics Review, Vol. 11, pp. 134-161.

Feldman, Allan M. and Singh, Ram (2019), 'Equilibria under Negligence Liability: How the standard claims fall apart,' Centre for Development Economics, Delhi School of Economics Working Paper No.300.

Geistfeld, Mark (2001), "Economics, Moral Philosophy, and the Positive Analysis of Tort Law," in Gerald J. Postema ed., Philosophy and the Law of Torts, 250-75, Cambridge University Press.

Goerke, Laszlo (2002), ' Accident Law: Efficiency May Require an Inefficient Standard, German Economic Review 3, 43-51.

Goerke, Laszlo (2002), German Economic Review 3(1): 43-51

Hindley, B. and B. Bishop (1983), 'Accident liability rules and externality', 3 International Review of Law and Economics, 59-68.

Holmstrom, Bengt (1982), 'Moral Hazard in Teams', The Bell Journal of Economics, Vol. 13, No. 2 , pp. 324-340.

Guerra, Alice (2015), 'Essays on the Economic Analysis of Tort Law', PhD Thesis, accessed on March 2020 at https ://ediss.sub.uni - hamburg.de/volltexte/2017/8358/pdf/Dissertation.pdf

Hylton Keith N (2001), 'The Theory of Tort Doctrine and The Restatement of Torts' 54 Vanderbilt Law Review, 1413 .

Jain, Satish K and Singh, Ram, (2002), 'Efficient Liability Rules: Complete Characterization', Journal of Economics, Vol. 75, No 2, 105-24.

Jain, Satish K. 'Decoupled liability and efficiency: An impossibility theorem', Review of Law and Economics, 8, 697718.

Kaur, Harshil Rajendra P. Kundu (2019), 'Efficient Liability Assignment With Decoupling: An Example' SSRN Electronic Journal, DOI: 10.2139/ssrn.3325340

Landes, William M. and Posner, R. A. (1987), The Economic Structure of Tort Law, Cambridge (MA), Harvard University Press.

Miceli, Thomas J. (1997), Economics of the Law: Torts, Contracts, Property, Litigation, Oxford, Oxford University Press.

Miceli, Thomas J. (2017), The Economic Approach to Law, Third Edition, Stanford University Press.

Parisi, Francesco and Fon, Vincy (2004), 'Comparative Causation,' 6, American Law and Economics Review, 345-368.

Parisi, Francesco and Singh, Ram (2010), 'The Efficiency of Comparative Causation', Review of Law and Economics, 6(2), pp. 219-245.

Polinsky, A. MitchelL(1989), An Introduction to Law and Economics, 2nd ed,Boston,Little,Brown and Co.

Polinsky, A. MitchelL(1980), 'Strict Liability vs. Negligence in a Market Setting', 70 American Economics Review; Papers and Proceeding 363-70.

Polinsky, A. Mitchell and Che, Yeon-Koo (1991), 'Decoupling Liability: Optimal incentives for Care and Litigation, 22 Rand Journal of Economics, 562-570.

Rubinfeld, Daniel L. (1987), 'The Efficiency of Comparative Negligence', 16 Journal of Legal Studies, 375-394. 
Schfer, Hans-Bernd and Mueller-Langer, Frank, (2009). 'Strict liability versus negligence.' Chapter, in: Michael Faure (ed.), Tort Law and Economics, chapter 1, Edward Elgar Publishing.

Shavell, Steven (1980). 'Strict liability versus negligence.' Journal of Legal Studies 9, 125. Steven Shavell (2007a), 'Do excessive legal standards discourage desirable activity?', Economic Letters, 95, 394397.

Steven Shavell (2007b), 'Liability for Accidents', in Handbook of Law and Economics, 142-182, Edited by A. Mitchell Polinsky and Steven Shavell, North Holland.

Steven Shavell (1987), Economic Analysis of Accident Law, Cambridge (MA), Harvard Univ. Press. Singh, Ram (2004), "Full Compensation Criteria: An Enquiry into Relative Merits", European Journal of Law and Economics, 2004, Vol. 18, pp. 223-237.

Singh, Ram (2006), "On the Existence and Efficiency of Equilibria under Liability Rules, National Bureau of Economic Research (NBER), Cambridge M.A., Working Papers No 12625

Singh, Ram (2007a), 'Comparative Causation and Economic Efficiency: When Activity Levels are Constant' Review of Law and Economics, Vol. 3, pp. 383-406.

Singh, Ram (2007b), "Causation-consistent' liability, Economic Efficiency and the Law of Torts", International Review of Law and Economics, Vol. 27, pp. 179-203.

Singh, Ram (2009), "Risk, Informational Asymmetry and Product Liability: An enquiry into conflicting objectives, Pacific Economic Review, 2009, Vol. 14, pp. 89-112. 


\section{Tables 1-3}

\section{Appendix (Tables)}

Table 1: Based on class $\mathbf{C} 3$

\begin{tabular}{|c|c|c|c|c|}
\hline $\begin{array}{c}\text { Function } \\
\text { parameters }\end{array}$ & $\begin{array}{c}\text { FOC } \\
\text { solution }\end{array}$ & $\begin{array}{c}\mathrm{NSB}(.) \text { at } \\
\text { FOC solution }\end{array}$ & $\begin{array}{l}\text { First Best } \\
\text { solution }\end{array}$ & $\begin{array}{l}\text { NSB(.) at } \\
\text { First Best }\end{array}$ \\
\hline $\begin{array}{l}\delta=0.1 \\
D=50\end{array}$ & $\begin{array}{l}0.05607 \\
0.33719 \\
0.05607 \\
0.33719\end{array}$ & 0.33068 & $\begin{array}{c}24.96370 \\
0 \\
5.13773 \times 10^{-5} \\
34.32330\end{array}$ & 2.50358 \\
\hline $\begin{array}{c}\delta=0.01 \\
D=50\end{array}$ & $\begin{array}{l}0.05829 \\
0.35363 \\
0.05829 \\
0.35363\end{array}$ & 0.34097 & $\begin{array}{c}2499.96 \\
0 \\
5.0141 \times 10^{-7} \\
352.551\end{array}$ & 25.0004 \\
\hline $\begin{array}{c}\delta=0.001 \\
D=50\end{array}$ & $\begin{array}{l}0.05852 \\
0.35529 \\
0.05852 \\
0.35529\end{array}$ & 0.34202 & $\begin{array}{c}2.50000 \times 10^{5} \\
0 \\
5.00141 \times 10^{-9} \\
3.53453 \times 10^{3}\end{array}$ & $2.50000 \times 10^{2}$ \\
\hline $\begin{array}{c}\delta=0.00001 \\
D=50\end{array}$ & $\begin{array}{l}0.05855 \\
0.35547 \\
0.05855 \\
0.35547\end{array}$ & 0.34213 & $\begin{array}{c}2.5 \times 10^{9} \\
0 \\
5.00002 \times 10^{-13} \\
3.53553 \times 10^{5}\end{array}$ & $2.50000 \times 10^{4}$ \\
\hline $\begin{array}{c}\delta=0.1 \\
D=5000\end{array}$ & $\begin{array}{l}0.00498 \\
1.99504 \\
0.00498 \\
1.99504\end{array}$ & 0.09542 & $\begin{array}{c}24.99650 \\
0 \\
5.01346 \times 10^{-7} \\
3.52528 \times 10^{2}\end{array}$ & 2.50035 \\
\hline $\begin{array}{l}\delta=0.001 \\
D=5000\end{array}$ & $\begin{array}{l}0.00505 \\
2.01205 \\
0.00505 \\
2.01205\end{array}$ & 0.09641 & $\begin{array}{c}2.50000 \times 10^{5} \\
0 \\
5.00014 \times 10^{-11} \\
3.53543 \times 10^{5}\end{array}$ & $2.50000 \times 10^{2}$ \\
\hline $\begin{array}{c}\delta=0.00001 \\
D=5000\end{array}$ & $\begin{array}{l}0.00505 \\
2.01222 \\
0.00505 \\
2.01222\end{array}$ & 0.09642 & $\begin{array}{c}2.49994 \times 10^{9} \\
0 \\
9.07487 \times 10^{-15} \\
3.54363 \times 10^{6}\end{array}$ & $2.50000 \times 10^{4}$ \\
\hline
\end{tabular}

Columns 2 and 4 give solutions to the maximization problem in the order $s, x, t, y$ from top to bottom. 
Table 2: Based on class $\mathbf{C} 4$

\begin{tabular}{|c|c|c|c|c|}
\hline $\begin{array}{c}\text { Function } \\
\text { parameters }\end{array}$ & $\begin{array}{c}\text { FOC } \\
\text { solution }\end{array}$ & $\begin{array}{c}\mathrm{NSB}(.) \text { at } \\
\text { FOC solution }\end{array}$ & $\begin{array}{l}\text { First Best } \\
\text { solution }\end{array}$ & $\begin{array}{l}\text { NSB(.) at } \\
\text { First Best }\end{array}$ \\
\hline $\begin{array}{c}\delta=2 \\
D=50\end{array}$ & $\begin{array}{l}0.05111 \\
0.29926 \\
0.05111 \\
0.29926\end{array}$ & 0.08691 & $\begin{array}{c}1.00003 \\
0 \\
0 \\
0\end{array}$ & 1.0 \\
\hline $\begin{array}{c}\delta=5 \\
D=50\end{array}$ & $\begin{array}{l}0.22643 \\
1.18238 \\
0.22643 \\
1.18238\end{array}$ & 0.86443 & $\begin{array}{c}2.50008 \\
0 \\
0 \\
0\end{array}$ & 6.25 \\
\hline $\begin{array}{c}\delta=8 \\
D=50\end{array}$ & $\begin{array}{l}0.50000 \\
2.00000 \\
0.50000 \\
2.00000\end{array}$ & 3.00000 & $\begin{array}{c}4.00003 \\
0 \\
0 \\
0\end{array}$ & 16.0 \\
\hline $\begin{array}{c}\delta=10 \\
D=500\end{array}$ & $\begin{array}{l}0.09450 \\
2.93700 \\
0.09450 \\
2.93700\end{array}$ & 0.66748 & $\begin{array}{c}5.00004 \\
0 \\
0 \\
0\end{array}$ & 25.0 \\
\hline $\begin{array}{c}\delta=15 \\
D=500\end{array}$ & $\begin{array}{l}0.20254 \\
4.53164 \\
0.20254 \\
4.53164\end{array}$ & 2.12025 & $\begin{array}{c}7.50006 \\
0 \\
0 \\
0\end{array}$ & 56.25 \\
\hline $\begin{array}{c}\delta=20 \\
D=500\end{array}$ & $\begin{array}{l}0.34858 \\
6.10095 \\
0.34858 \\
6.10095\end{array}$ & 4.84493 & $\begin{array}{c}10.0001 \\
0 \\
0 \\
0\end{array}$ & 100.0 \\
\hline
\end{tabular}

Columns 2 and 4 give solutions to the maximization problem in the order $s, x, t, y$ from top to bottom. 
Table 3: Based on class $\mathbf{C 5}$

Function FOC NSB(.) at First Best NSB(.) at parameters solution FOC solution solution First Best

\begin{tabular}{|c|c|c|c|c|}
\hline $\begin{array}{c}\delta=1 \\
D=50\end{array}$ & $\begin{array}{l}0.03579 \\
0.16894 \\
0.03579 \\
0.16894\end{array}$ & 0.24023 & $\begin{array}{c}0.12276 \\
0 \\
0.00989 \\
1.47753\end{array}$ & 0.25786 \\
\hline $\begin{array}{c}\delta=2 \\
D=50\end{array}$ & $\begin{array}{l}0.02373 \\
0.04459 \\
0.02373 \\
0.04459\end{array}$ & 0.18161 & $\begin{array}{c}0.02749 \\
0 \\
0.02099 \\
0.17242\end{array}$ & 0.18176 \\
\hline $\begin{array}{c}\delta=1 \\
D=100\end{array}$ & $\begin{array}{l}0.02661 \\
0.31561 \\
0.02661 \\
0.31561\end{array}$ & 0.20857 & $\begin{array}{c}0.13526 \\
0 \\
0.00456 \\
2.67777\end{array}$ & 0.24375 \\
\hline $\begin{array}{c}\delta=2 \\
D=100\end{array}$ & $\begin{array}{l}0.01873 \\
0.18432 \\
0.01873 \\
0.18432\end{array}$ & 0.16373 & $\begin{array}{c}0.03308 \\
0 \\
0.01124 \\
0.81889\end{array}$ & 0.16609 \\
\hline $\begin{array}{c}\delta=1 \\
D=500\end{array}$ & $\begin{array}{l}0.01293 \\
0.77121 \\
0.01293 \\
0.77121\end{array}$ & 0.14728 & $\begin{array}{c}0.14974 \\
0 \\
0.00083 \\
7.65261\end{array}$ & 0.22558 \\
\hline $\begin{array}{c}\delta=5 \\
D=500\end{array}$ & $\begin{array}{l}0.00516 \\
0.30292 \\
0.00516 \\
0.30292\end{array}$ & 0.08028 & $\begin{array}{c}0.00637 \\
0 \\
0.00431 \\
0.78401\end{array}$ & 0.08060 \\
\hline
\end{tabular}

Columns 2 and 4 give solutions to the maximization problem in the order $s, x, t, y$ from top to bottom. 